\title{
Livros didáticos - fragmentos e retalhos de (in)formação literária?
}

\section{Textbooks - fragments and pieces of literary (in)formation?}

\author{
Tânia Regina Oliveira Ramos* \\ Gizelle Kaminski Corso**
}

\begin{abstract}
Resumo: A proposta deste texto é lançar reflexões que partem da pergunta evidenciada em seu título e entender a razão da permanência dos livros didáticos em sala de aula, especialmente como instrumento de mediação para o ensino de literatura. Neste texto também não deixamos de pensar no ensino a distância e do quanto ele se vale do modelo do livro didático (livro-texto) para a efetivação da relação ambiente virtual e materialidade de apoio.

Palavras-chave: Livros didáticos. Literatura e ensino. Leitura.

Abstract: The purpose of this paper is to reflect on the question highlighted on its title and understand why textbooks are still used in classrooms, especially as an instrument of mediation for the teaching of literature. This text also reflects about distant learning and how much it relies on the school book (textbook) as a model to establish the relation between the virtual environment and concrete support.
\end{abstract}

Keywords: Textbooks. Literature and teaching. Reading.

Só no quarto ano trocamos os livros ilustrados por um volume mais grosso, sem enfeites: era a antologia de Olavo Bilac e Manuel Bonfim.

(Paulo Mendes Campos. Primeiras Leituras).

Nesta primeira década do século XXI, o avanço e a incorporação de novas tecnologias e as mudanças de paradigmas já iniciados nas últimas décadas do século XX nos levaram paradoxalmente à constatação da permanência

* Professora doutora. Universidade Federal de Santa Catarina - UFSC. E-mail: taniaramos@floripa. com.br.

** Doutoranda. Universidade Federal de Santa Catarina - UFSC. E-mail: gikacorso@gmail.com. 
do objeto livro e da sua adjetivação didática como o suporte para a mediação do aluno e do professor no processo ensino e aprendizagem.

Vejamos o que nos respondeu uma turma de professoras e de professores de ensino básico, em um recente encontro sobre literatura, diante da pergunta: "que livro marcou a sua infância e a sua adolescência na escola?". Um número significativo delas e deles lembrou de seus livros didáticos, suas capas, suas antologias, seus textos. Muitos inclusive apontaram seus primeiros livros ou suas cartilhas. Quando, a partir deste contraponto, perguntamos aos alunos e às alunas da disciplina Literatura e Ensino, do curso de Letras Português da UFSC, futuros professores, se conseguiam se lembrar da sua cartilha, do seu primeiro livro de leitura, naturalmente a resposta foi antecedida pela pergunta: o que é cartilha, o que é primeiro livro de leitura? Diante do anacronismo da pergunta pedimos que falassem, então, do primeiro livro, aquele onde aprenderam a ler, e a maioria deles, nascidos já no final da década de 80 e alguns no início da década de 90 , não lembrava quando aprenderam a ler e falaram de suas apostilas e de folhas soltas de exercícios e textos.

Se o primeiro livro de leitura não é mais um marco, nem deixa marcas como ocorria para as gerações anteriores, a pergunta, mesmo assim, incitou-nos a escrever este texto, que ensaia ideias para futuras pesquisas, como pensar na forma pela qual se dá a leitura da literatura na escola após os primeiros anos do ensino fundamental. Aqui entra a recuperação da presença do livro didático não como lembrança de infância, mas como material escolar, instrumento formal para a aprendizagem. Não vamos entrar no mérito dos livros didáticos em si, mas pensá-los na sua especificidade e na sua sobrevivência, inclusive no formato de "livro-texto" como material de apoio, diálogo, interação, no ensino superior a distância.

O livro didático é, segundo Marisa Lajolo e Regina Zilberman (1996), uma das modalidades mais antigas da expressão escrita para a efetivação da aprendizagem na escola. Supostamente antecedido pela Poética, de Aristóteles, e pela Institutio oratoria, de Marcus Fabius Quintiliano, o livro didático construiu a sua história como uma espécie de assistente fiel de grande parte dos professores.

Por uma explícita necessidade pragmática de seu uso e até pela possibilidade que ele oferece ao ser adotado por escolas, classes, turmas, séries, 
anos, passou pelo crivo de decretos e medidas, com as primeiras iniciativas desenvolvidas pelo Estado Novo, em 1937, que consistiram em distribuição e divulgação de obras de interesse educacional. Em 1968, foi criada a Fundação Nacional do Material Escolar (FENAME), com o Programa Nacional do Livro Didático, alterado em 1976, e, em 1985, a criação do Plano Nacional do Livro Didático, ${ }^{1}$ regulamentado pelo decreto ${ }^{\circ}$ 9154/85 que implementou o Programa Nacional do Livro Didático, o qual, em seu artigo $2^{\circ}$, estabelece $a$ avaliação rotineira dos materiais.

Os livros didáticos tornam-se, assim, fortes aliados dos professores por serem facilitadores da rotina docente, cujos conteúdos, organizados em unidades menores, ajudam a controlar o horário e evitar desperdício de conhecimento a ser dominado. Deste modo, professores precisam aliar o tempo para o aprendizado na escola aos extensos programas de ensino. Além disso, os livros didáticos, em seu formato como os conhecemos, permitem que os alunos tenham sempre todo o conteúdo organizado e sistematizado em unidades, capítulos e tópicos. Extremamente visuais, trazem seleção de textos, exercícios, que otimizam a vida dos professores, por disporem de pouco tempo para preparar suas aulas, e a dos alunos, que não precisam copiar conteúdos e avaliações do quadro, no tradicional movimento físico da cabeça, do olhar para a frente, do baixar a cabeça, de lembrar o que leu para reproduzir no caderno. Talvez poucos de nós que tenha passado por isso tenha refletido sobre a complexa atividade que é copiar do quadro e do esforço mental e físico que a atividade requer, geralmente exigida em finais da aula como tarefa a ser executada em casa. O livro didático e os exercícios nele contidos a cada unidade, além de mostrar ao professor onde deve chegar, permite que o aluno ganhe tempo, dizem os representantes das editoras em seus catálogos.

Nossa leitura em um primeiro momento está querendo pensar nos livros didáticos que contêm conteúdos de literatura ou práticas de leitura. Em muitos casos, os métodos/meios utilizados por professores estão longe de desenvolver a leitura propriamente dita quando se detêm no livro didático

\footnotetext{
${ }^{1}$ PNLD - parte das políticas públicas de educação desenvolvidas pelo MEC. Seu objetivo é a distribuição gratuita de LD para todos os alunos das escolas públicas do ensino fundamental no Brasil. O programa tem origem nas ações da antiga Fundação de Assistência ao Estudante e tomou formato de sua versão atual em 1985. Só a partir de 1996 teve início a avaliação de obras didáticas e desde 2000 passou a ser realizada por diferentes instituições encarregadas por área do conhecimento. No caso de língua portuguesa, que inclui a área de alfabetização, a análise vem sendo realizada pelo Centro de Alfabetização, Leitura e Escrita (CEALE, FaE, UFMG) da Faculdade de Educação da UFMG.
} 
e em seus fragmentos, trechos, pedaços de textos, o que distancia os alunos dos textos integrais e do próprio desejo de ler. O conhecimento de literatura constrói-se, ali, por meio de fragmentos e retalhos de informação literária.

É possível formar leitores com fragmentos literários? É mais profícua a leitura de fragmentos de um número $\mathrm{x}$ de livros ou a leitura integral e contextualizada de menos da metade deles? Cyana Leahy-Dios, em Educação literária como metáfora social: desvios e rumos, afirma o seguinte a respeito do livro didático:

Propondo-se facilitar o trabalho do professor, o livro didático limita sua criatividade e o domínio do conhecimento teórico, embora diminua a dependência discente da palavra do professor para obter sucesso acadêmico. Entretanto, como fonte única de informação factual e de saber literário, enfraquece os interesses e os limites investigativos, bloqueando a curiosidade intelectual. Apesar de nem sempre os alunos observados terem sido silenciados por estratégias autoritárias explícitas, foi possível perceber a pressão apassivadora causada pelos limites de tempo, pelo programa positivista, pela forte expectativa sociocultural de passar nos exames. (LEAHY-DIOS, 2000, p. 106).

Embora a maior preocupação de alguns alunos resida em "passar nos exames", independentemente do que e de como aprendem, e de alguns professores em "passar o(s) conteúdo(s)", quando tomado como fonte única de (in) formação, como afirma a professora e pesquisadora, o livro didático enfraquece os limites investigativos e bloqueia a curiosidade intelectual. E isso nos permite pensar que, bom ou ruim, adequado ou inadequado, o livro didático é ainda um dos contribuintes e patrocinadores (ou um dos responsáveis) pela formação do leitor brasileiro no ensino fundamental e médio. Em livro recentemente organizado e publicado sob a responsabilidade da professora Maria da Graça Costa Val, intitulado Alfabetização e Língua Portuguesa: Livros didáticos e práticas pedagógicas (2009), os professores Delaine Cafieiro e Hércules Tolêdo Correa, em seu texto "Abordagem de textos literários em livros didáticos de língua portuguesa de $5^{\mathrm{a}}$ a $8^{\mathrm{a}}$ séries", elaboram considerações importantes sobre a presença da literatura nos livros didáticos. A literatura, segundo consta nesse texto, até meados dos anos 70 , tinha status privilegiado na escola porque os textos que circulavam nos livros didáticos, bem como os selecionados por professores, eram os de caráter literário. Todavia, a necessidade da presença de gêneros diversos na escola - e aqui nos referimos aos gêneros do discurso -, aclamada pela chegada dos Parâmetros Curriculares Nacionais, tirou um 
pouco do espaço da literatura na sala de aula. Sérios problemas começaram a se instaurar: "livros didáticos e professores, passando a se dedicar mais a outros gêneros, acabaram por dar um tratamento uniforme aos textos provenientes de diferentes esferas sociais, como a jornalística, a publicitária, a política e, também, a literária." (CAFIEIRO; TOLÊDO, 2009, p. 157). Daí que a questão reside justamente em saber lidar com essas esferas diferentes porque textos jornalísticos, publicitários, políticos e literários, por exemplo, não podem ser lidos da mesma forma. É preciso conhecê-los e aprender a lidar - ler - com cada um deles, respeitando as peculiaridades de cada um. A literatura tem um modo particular de produção e leitura e, portanto, necessita de tratamento e envolvimento à parte.

Com relação à presença de textos integrais nas recentes publicações de livros didáticos, afirmam os professores-autores que aqueles ainda são raros, prejudicando o contato do aluno com o texto e sua circulação na sociedade. Experiências de leitura limitadas à dinâmica do fragmento podem acarretar "a falsa concepção de que texto de escola, texto de aula de português, é sempre 'pedaço' de texto". (CAFIEIRO; TOLÊDO, 2009, p. 164).

Encontrado em todas as etapas da escolarização de um indivíduo, o livro didático é, segundo Marisa Lajolo e Regina Zilbermann, "cartilha, quando da alfabetização; seleta, quando da aprendizagem da tradição literária; manual, quando do conhecimento das ciências ou da profissionalização adulta, na universidade" (LAJOLO; ZILBERMAN, 1996, p. 121). É imprescindível também citar que os livros didáticos são ainda os mais vendidos e disseminados entre professores, que os utilizam, geralmente, como única referência de ensino. E, apesar do berço ilustre, como afirmam as professoras, é o primo pobre da literatura:

texto para ler e botar fora, descartável porque anacrônico: ou ele fica superado dados os progressos da ciência a que se refere ou o estudante o abandona, por avançar em sua educação. Sua história é das mais esquecidas e minimizadas, talvez porque os livros didáticos não são conservados, suplantado seu "prazo de validade". (LAJOLO; ZILBERMAN, 1996, p. 120).

No entanto, o livro didático é o primo rico das editoras porque sua vendabilidade é certa; conta com o apoio do sistema de ensino e o abrigo do Estado, e é aceito por pais e educadores. Apenas a literatura infantil oferece-lhe concorrência: mercado cativo e sempre crescente. Por outro lado, professores 
geralmente alegam que alunos não gostam de ler, mas, na maioria das vezes, acabam lendo menos do que os próprios alunos. Como formar leitores sem ser um leitor? Muitas vezes os professores, por falta de tempo, detêm-se apenas nos resumos de obras para terem uma ideia do seu "conteúdo". Se a literatura depende do modo como é ensinada/transmitida pelos professores, e a leitura literária é geralmente trabalhada em fragmentos, trechos, pedaços de textos, como formar leitores de literatura sem ser via dinâmica do fragmento?

Os fragmentos (ou retalhos) possuem sua carga de relevância textual, mas não podem ser levados em conta como única saída de ensino. Disso podem resultar atividades descontextualizadas, dispersas e fragmentadas que dificilmente chamam a atenção ou despertam interesse dos alunos. Assim, próprios para instruir, os livros didáticos deveriam ser vistos como uma alternativa a mais na vida de qualquer professor de cada disciplina, e não como única fonte de pesquisa e ensino. O professor português Carlos Ceia, em A literatura ensina-se? (2004), expõe a situação em que se encontram os professores do ensino básico em Portugal (correspondente ao ensino fundamental no Brasil):

No ensino básico, os estudos literários estão nas mãos de professores que não se sentiram preparados para essa função pelas instituições que os formaram, pelo que gradualmente adoptam um modus faciendi cada vez mais padronizado, consistindo na repetição de exercícios de receituário publicados de forma a normalizar todas as leituras possíveis de um texto literário constante do programa oficial; a rigor, não há qualquer descoberta da escrita e da leitura criativas; neste nível, o profissional de literatura é um profissional que não faz literatura, que está convencido que é incapaz de fazer crítica literária pelas suas próprias mãos e cabeça e, pior do que tudo isto, defende com fervor que não tem a obrigação de ir mais além das sugestões de leitura dos manuais, ou seja, a função do profissional de literatura passar a ser unicamente a de assegurar que um dado manual e um dado conjunto de leituras programadas não sejam desvirtuados. (CEIA, 2004, p. 27).

A afirmação de Carlos Ceia acima faz referência ao profissional das Letras que sai da Universidade sentindo-se despreparado para atuar em sala de aula e incapaz de produzir literatura e crítica literária. É claro que isso não pode ser visto de maneira generalizada, mas é algo evidente. É muito mais cômodo ler uma análise de outrem de alguma obra (ou mesmo a do livro didático), apropriar-se de determinados pontos, disseminá-los em sala de aula, do que produzir uma leitura crítica. Isso ocorre especialmente com textos 
contemporâneos, cuja produção de leituras críticas é bastante incipiente. $\mathrm{Na}$ dúvida de saber se sua leitura está correta (se é que isso realmente existe), muitos professores acabam deixando de lado obras que ainda não possuem uma considerável fortuna crítica por receio de caírem em armadilhas, por medo de desvendarem o novo e por se sentirem inseguros para efetuar uma possível leitura.

Em entrevista concedida a Rony Farto Pereira no jornal Proleitura, Egon de Oliveira Rangel, professor e coordenador em processos de Avaliação do Livro Didático por vários anos, fez a seguinte afirmação a respeito do que seria a qualidade de um livro didático (LD): "a qualidade de um LD é definida, sempre, por referência a um corpo de princípios, valores e critérios, explícitos ou não, que sintetizam o que uma determinada época pensa e espera do ensino de língua materna" (RANGEL, 1998, p. 1). E aqui vale acrescentar: o livro didático é definido de acordo com o que determinados elaboradores, dos quais boa parcela não atua na escola, concebem o como e o que deve ser apre(e)ndido pelos estudantes. Por outro lado, o livro didático é utilizado pelos alunos, mas de fato, dirige-se ao professor, que nem sempre acaba sendo um bom mediador. Se muitos deles nem sempre são completamente adequados para o ensino em sala de aula, por trazerem conceitos e informações equivocadas, deficiência metodológica e insuficiência teórica, a melhor saída seria, então, dispensá-los das aulas?

Para dispensar o LD é preciso ter coisa melhor a oferecer. Se o LD de má qualidade for o parâmetro, é muito mais fácil, para um grupo de educadores reunidos numa escola minimamente decente, selecionar e mesmo elaborar, com vantagens, materiais alternativos. Mas acredito que, mesmo no caso de boa parte dos livros que o Guia classifica como recomendados com ressalvas, não é fácil dispor de coisa melhor. Se a alternativa é selecionar outros materiais didáticos, o universo não será muito diferente do que se apresenta no LD. (RANGEL, 1998, p. 4).

Se, como afirma Egon de Oliveira Rangel, mesmo com boa vontade por parte de professores, não é fácil apresentar algo muito diferente do que está contido nos livros didáticos, podemos pensar que, em matéria de literatura, o que deve ter um lugar destacado nas aulas é a insubstituível leitura de livros. E isso tem a ver com a afirmação do professor Carlos Ceia, ao arriscar uma proposta do que seria o melhor manual aos alunos de literatura: 
O melhor manual que se pode recomendar aos alunos de literatura é o pior manual que se pode dar ao professor de hoje: um manual sem textos de apoio, sem notas, sem linhas de leitura, sem propostas de actividades, isto é, apenas com os textos literários em estado puro e sem a presença de críticas ou propostas redutoras. (CEIA, 2004, p. 52).

A afirmação do professor português torna evidente que o melhor manual para os alunos seria justamente o pior para os professores, por terem de lidar diretamente com os textos literários, "em estado puro", alheios a críticas ou textos de apoio. Nesse manual ideal o texto viria em primeiro lugar, substituindo, assim, "a escola", "o movimento", "o autor", os monemas da língua, como definiu Roland Barthes ${ }^{2}$.

Concordamos que o texto literário deve vir em primeiro lugar, e procure ser o pontapé inicial para as discussões, inquietações e reflexões, mas, como seriam as aulas de literatura sem um pouco de presença da crítica ou mesmo de textos de apoio? Nessa esteira, e também com "olhos para o presente", a professora Maria Graciete Vilela (2005) reconhece devida importância a manuais, florilégios, antologias, coleções que, segundo ela, permitem a alunos e professores o contato com trabalhos sérios que intentam fortalecer a reflexão dos textos literários. Vilela não descarta dados e leituras complementares, mas assevera que:

As informações sobre autores e contexto, as leituras críticas complementares, a existirem no manual, devem estar claramente distanciadas dos textos e devem fornecer dados precisos, concisos e relevantes. As propostas de actividades, ou propostas de leitura (as editoras, hoje, não dispensam este material) devem incentivar o aluno a ter uma experiência pessoal de leitura, devem dar-lhe uma possibilidade de conversar com o texto, de averiguar o modo de tricotar a renda da linguagem do texto, não esquecendo que os escritores são os guardadores da linguagem precisa, clara e luminosa e que, muitas vezes, a "corrompem" porque a conhecem demasiado bem. (VILELA, 2005, p. 639-640).

Assim, as noções biográficas, e mesmo os fragmentos que delineiam o contexto em que tal obra foi escrita, sempre presentes em todo o tipo de "manuais", e que ocupam um espaço que poderia ser ocupado por textos integrais, possuem sua eficiência quando precisos, concisos e relevantes, mas

\footnotetext{
${ }^{2}$ Em Reflexões a respeito de um manual (1969 [1988]).
} 
a professora alerta para o fato de que o aluno tenha, acima de tudo, "uma experiência pessoal de leitura", de conversa com o texto e suas tessituras. E se aparecem no manual, na apostila, no livro, atividades que procurem "encaixotar" a literatura, e solicitem para que o aluno escreva qual estilo de época "voltou-se para uma realidade subjetiva buscando a oposição entre matéria e espírito; a purificação, por meio da qual o ser atinge as regiões etéreas, o espaço infinito, a sublimação", que o professor procure conjugar com o texto literário. Será que a "sobrevalorização da sonoridade, da musicalidade e fluidez do verso" somente ocorre no Simbolismo?

Acreditamos que é necessário discernimento crítico por parte do professor para saber enfatizar determinados aspectos em lugar de outros quando da utilização desses "suportes" (apostilas, livros didáticos, fotocópias) que em sua maioria recorrem à historiografia. $\mathrm{O}$ que deve ser desejado é que o professor faça dos conteúdos do livro didático, e da forma como são apresentados, uma oportunidade de reflexão tanto para ele quanto para os alunos, pois o importante é serem leitores críticos do que lhes é oferecido como texto $\mathrm{e}(\mathrm{m})$ sua materialidade.

\section{II}

É neste ponto que a nossa leitura se reporta diretamente para a paradoxal experiência: escrevemos juntas um "livro didático" sobre Literatura e Ensino para o Curso de Letras Português, ${ }^{3}$ da UFSC, modalidade a distância, depois de vivenciar algumas experiências, ou seja, ministrar para o mesmo curso a disciplina Literatura Brasileira III - Literatura Contemporânea e preparar um material de História da Literatura Brasileira para ser adaptado às especificidades do Curso de Libras - EAD, UFSC. O futuro nos remeteu ao passado, pois tivemos que pensar sobre todas as questões que apontamos como fragilidades do livro didático. ${ }^{4}$ Um exercício de metalinguagem. Reaprendemos a escrever manuais, estudos dirigidos, provas de múltipla escolha, trabalhamos com excertos, antologias, críticas e literárias, escrevendo discursiva e cartesianamente nossas aulas, começo, meio e fim, ilustrando com

\footnotetext{
${ }^{3}$ Literatura e ensino (2010).

${ }^{4}$ A primeira reflexão sobre estas questões e as ideias aqui desenvolvidas foram pela primeira vez apresentadas no Congresso da ABRALIC, USP, 2008, no GT Memória Cultural, coordenado pelo Prof. Dr. Luiz Roberto Veloso Cairo.
} 
fragmentos, selecionando o cânone entre os cânones, estabelecendo links a partir de rodapés. Há muito tempo a historiografia e o discurso crítico não haviam sido tão recortados e tão seletivos. Nunca mais tínhamos nos valido das certezas positivistas da historiografia e nunca carecemos tanto da ausência de uma história das visualidades e dos acervos digitais.

Em pleno século XXI nos reportamos, então, às reflexões acerca dos manuais, feitas por Roland Barthes em 1969 (BARTHES, 1988), ao império da eloquência, evocando a retórica disciplinar do século XVIII e XIX estudado por Roberto Acizelo de Souza e, mais recentemente, à reflexão sobre as antologias feitas por Luiz Rufatto, para entender essa nossa nova produção acadêmica. Como nos diria Cazuza: "Eu vejo o futuro repetir o passado, eu vejo um museu de grandes novidades".

Para ilustrar, vamos aos manuais. Roland Barthes, em "Reflexões a respeito de um manual", diz que a história da literatura é um objeto essencialmente escolar, que só existe por seu ensino. A literatura, por sua vez, como já mencionamos anteriormente, é um objeto de ensino feita de monemas: autores, obras, escolas, movimentos, gêneros e séculos. Sobre esses objetos a combinação de traços e predicados, quase sempre em oposição: Romantismo/ Classicismo; Romantismo/Realismo produzindo individualidades ou certos indivíduos literários. É assim que nos manuais, os próprios séculos acabam por apresentar-se sempre de maneira paradigmática. Diz diretamente Barthes sobre estas questões: "O que estou dizendo é simplesmente a amostra do que se poderia imaginar como uma espécie de pequena gramática da nossa literatura, gramática que produziria umas espécies de individuações estereotipadas: os autores, os movimentos, as escolas" (BARTHES, 1988).

A gramática de nossa literatura precisa, no entanto, na feitura dos livros didáticos que tanto criticamos, de textos, exemplos, remissões. É neste momento que retomamos a leitura de Luiz Rufatto, escritor contemporâneo, colecionador e organizador de antologias. Antes de analisar a primeira antologia brasileira de contos, excluídas as de fins didáticos, Contos Brasileiros, uma edição de 404 páginas, publicada pela Livraria Garnier do Rio de Janeiro, impressa na Bélgica em 1922, organizada pelos poetas Alberto de Oliveira e Jorge Jobim (poeta bissexto e pai de Antônio Carlos Jobim), ${ }^{5}$ Luiz Rufatto posiciona-se a respeito das antologias afirmando que:

\footnotetext{
${ }^{5}$ Estes dados são todos retirados do artigo de Luiz Rufatto citado anteriormente.
} 
As antologias servem, de maneira geral, para evidenciar e consolidar nomes, e serão tanto mais significativas quanto maior a capacidade de apreensão do "espírito do tempo", demonstrada pelo responsável pela escolha dos autores. Ao fim e ao cabo, trata-se de um esforço para normatizar o gosto literário, baseado em interesses os mais diversos, sejam da sociedade, do mercado editorial ou de grupos marginalizados ou não [...]. Mesmo as seletas geracionais, que prescindem dessa mescla, necessitam, para serem aceitas, de um garantidor que pode ser o autor de prestígio que assina a apresentação do livro, a editora que empresta crédito ao projeto, ou o grupo que sustenta a ação. ${ }^{6}$

Neste futuro repetindo o passado naquilo que não devemos hoje chamar apenas de livro, mas material impresso, guia de estudo, porque o objeto livro, seu conteúdo, fica a serviço da interação virtual, vemos a combinação do manual pensado por Barthes com uma estética das antologias, dos fragmentos, que buscam operar neste novo perfil de universitários a assimilação das informações, o gosto, o pensamento crítico, motivando e remetendo à leitura das obras como um todo. Uma motivação a distância, ainda que amparados nos polos por uma estrutura física, não mais mediados pelo pensamento imediato e pela presença de um professor da disciplina, cuja voz permanece imperativa nos comandos escritos: Leia. Leia mais!

Não é em vão que os intermediários vão se chamar tutores. A cátedra volta a existir: graduados, mestrandos, mestres, doutorandos e doutores, assistentes, tornam-se tutores, estabelecendo o diálogo virtual e presencial, uma imprescindível participação colaborativa.

Na dúvida e na tensão do diálogo como este que estabelecemos agora - porque escrevemos o que pode se chamar de livro didático ou material impresso, a voz da experiência provisória e a crítica debatem-se na avaliação do material e nas próprias escolhas. As certezas da historiografia, as assertivas informacionais, a gramática dos estilos, os manuais, as múltiplas escolhas, as antologias, as escolhas de textos, os fragmentos, têm nos permitido alguns acertos provisórios nessa forma de ensino.

Retomamos Roland Barthes quando nos recomenda fazer de nós mesmos o centro dessa história. E nesse ponto entra Bakhtin (2000) e a busca ao diálogo, o dialogismo desejado, a escritura, ao mesmo tempo como subjetividade e comunicabilidade, a existência sempre de um outro, nos

\footnotetext{
${ }^{6}$ RUFATTO, Luiz. Idem. Ibidem.
} 
textos que escrevemos. Porque a despeito dos manuais, dos fragmentos, do gosto literário pelo exemplo, pelo antológico, pela seletiva dos cânones, o livro didático - ou como querem chamar - material impresso, é realmente a materialidade de alguma coisa que a presença nos desobriga. Você lembra o que vimos na Unidade 3? Recupere o início de nossa explicação. Volte à aula anterior. Reveja agora o que vimos sobre a Carta de Pero Vaz de Caminha. Localize agora o poema "Se eu morrer amanhã " do poeta romântico Álvares de Azevedo em <www.literaturabrasileira.ufsc.br> Leia. Leia mais! Gestos automáticos para uns, gestos de interpretação para outros. Buscas, perdas, memória e esquecimento.

Nesta geografia e nos deslocamentos teóricos, a síntese da nossa experiência desejou trazer à tona questões contemporâneas das necessidades pragmáticas que estabelecemos com os arquivos da memória e com a história da literatura. Ou das literaturas. Há processos contínuos de mudança na relação que se estabelece entre o conhecimento acumulado e uma prática que precisa ser renovada, mas que se submete àquele suporte que tem se mostrado como o mais poderoso auxiliar para os estudos de literatura: o livro, o impresso, a sistematização historiográfica, os textos, mesmo que sujeitos a novos formatos.

A despeito de pressentirmos "um museu de grandes novidades", muito mais integradas do que apocalípticas, rendemo-nos ao mais frágil dos instrumentos de apoio, porque no momento em que escrevemos, tudo o que aqui representamos - na provisoriedade de nossa experiência - já atingiu o estatuto universitário de grandes projetos disseminatórios: o ensino a distância e do quanto ele se vale do modelo do livro didático para a concretização do processo ensino e aprendizagem.

O material que estamos produzindo na UFSC para outros ou para o Outro, cuja depositária é a $\mathrm{CAPES}^{7}$ - manuais, guias, antologias - exercício

\footnotetext{
${ }^{7}$ Art. 25. À Diretoria de Educação a Distância compete: I - fomentar as instituições públicas de ensino superior e polos municipais de apoio presencial, visando a oferta de qualidade de cursos de licenciatura na modalidade a distância; II - articular as instituições públicas de ensino superior aos polos municipais de apoio presencial, no âmbito da Universidade Aberta do Brasil - UAB; III - subsidiar a formulação de políticas de formação inicial e continuada de professores, potencializando o uso da metodologia da educação a distância, especialmente no âmbito da UAB; IV - apoiar a formação inicial e continuada de profissionais da educação básica, mediante concessão de bolsas e auxílios para docentes e tutores nas instituições públicas de ensino superior e tutores presenciais e coordenadores nos polos municipais de apoio presencial; e V - planejar, coordenar e avaliar, no âmbito das ações de fomento, a oferta de cursos superiores na modalidade a distância pelas instituições públicas e a infraestrutura física e de pessoal dos polos municipais de apoio presencial, em apoio à formação inicial e continuada de professores para a educação básica.
} 
de escrita por tantos anos desaprendido, quer resultar no pacto entre o lembrar e o esquecer sem comprometer os atos de ver na gramática e na tradição de nossa literatura a mesma história tantas vezes lida: autores, obras e textos.

O que quisemos demonstrar a partir desta leitura, que escrevemos atando a ponta de duas vidas em diferentes etapas de formação e de atuação, é que o livro, aliado às novas tecnologias, não mais se ressentirá da falta de um diálogo com o pictórico, com o fílmico, com o imagético, com o sonoro, com a literatura em meio eletrônico, esses campos instáveis que ao lado da palavra escrita são produtores de sentidos. Se neste texto pensamos nos livros didáticos, de Comunicação e Expressão, Linguagens, Português, Literatura, Língua Portuguesa, dialogando abertamente com o ensino a distância, o fizemos porque nessa modalidade de ensino eles não mais apenas surgem como suporte a professores, tutores e alunos, mas substituem uma fal $(t) a$, tornam-se presença e ausência, fragmentos e retalhos, mosaicos para múltiplas leituras e tessituras. O sistema literário deve se somar ao sistema figurativo de uma memória cultural e de novas tecnologias para que não mais precisemos reconhecer ou ter que discutir a fragilidade do livro didático ou livro-texto. Eles devem sempre servir de suporte de aproximação dos alunos com a sistematização dos conteúdos de qualquer nível de ensino, seja pela ilustração (no sentido de conhecimento e de visualidade), seja pela síntese, seja por um modo de interação cooperativa entre aquele que ensina e aquele que apre(e)nde conteúdos. O importante é que a resposta à pergunta de Roland Barthes em reflexões a respeito de manuais de literatura - o que fica da literatura depois do colégio? - seja dada pelas lembranças e esquecimentos dos professores e dos jovens, futuros professores, com os quais iniciamos este texto, mas nunca mais com a amarga reflexão de Graciliano Ramos a respeito de seu manual escolar: "Um grosso volume escuro, cartonagem severa. Nas folhas delgadas, incontáveis, as letras fervilhavam, miúdas, e as ilustrações avultavam num papel brilhante como rasto de lesma ou catarro seco" (2003, p. 12).

\section{Referências}

GOMBRICH, Sir Ernst. História da arte. [Trad. Álvaro Cabral]. Rio de Janeiro: LTC Editora, 1999.

ANDRADE, Claudete Amália Segalin de. Dez livros e uma vaga: a leitura de literatura no vestibular. Florianópolis: Ed. da UFSC, 2003.

BAKHTIN, M. M. Estética da criação verbal. 3. ed. São Paulo: Martins Fontes, 2000. 
BARTHES, Roland. A morte do autor. In: O rumor da língua. São Paulo: Editora Brasiliense, 1988, p. 65-70.

. Reflexões a respeito de um manual. In: . O rumor da língua. São Paulo: Editora Brasiliense, 1988, p. 35-59.

CEIA, Carlos. A literatura ensina-se? Estudos de Teoria Literária. Edições Colibri: Faculdade de Letras de Lisboa, Portugal, 2004.

LAJOLO, Marisa; ZILBERMAN, Regina. A formação da leitura no Brasil. São Paulo: Ática, 1996.

LEAHY-DIOS, Cyana. Educação literária como metáfora social: desvios e rumos. Niterói, RJ: EDUFF, 2000.

RAMOS, Graciliano. Infância. Rio de Janeiro: Record, 2003.

RAMOS, Tânia Regina Oliveira; CORSO, Gizelle Kaminski. Literatura e ensino: $5^{\circ}$ período. Florianópolis, SC: UFSC, 2010.

RANGEL, Egon de Oliveira. Para não arruinar talentos. Proleitura. FCL, UNESP de Assis, ano 6, n. 23, p.1-4, dez. 1998. Entrevista.

RITER, Caio. A formação do leitor literário em casa e na escola. São Paulo: Biruta, 2009.

SANT'ANNA, Affonso Romano de. Paródia, paráfrase \& cia. 6.ed. São Paulo: Ática, 1998.

VAL, Maria da Graça Costa (Org.). Alfabetização e língua portuguesa: livros didáticos e práticas pedagógicas. Belo Horizonte: Autêntica Editora, Ceale/FaE/UFMG, 2009. (Coleção Linguagem e Educação).

VILELA. Maria Graciete. Sobre o ensino da literatura: os ensinamentos de Xerazade. In: G. RIO-TORTO, G.; FIGUEIREDO, O.; SILVA, F. (Coord.). Estudos em homenagem ao Professor Doutor Mário Vilela (v. 2, p. 633-641). Porto: Faculdade de Letras da Universidade do Porto, 2005. Disponível em: <http://ler.letras.up.pt/uploads/ficheiros/4593.pdf>. Acesso em: 13 jul. 2010.

Recebido para publicação em 8 nov. 2010.

Aceito para publicação em 14 dez. 2010. 